\title{
Optimization of Prestressed Anchor Blocks with Arch Cavity
}

\author{
Jianhui Si, Rong Fan, Zheng Jian \\ School of Civil Engineering and Architecture, Xi an University of technology, Xi an, 71048, China
}

\begin{abstract}
This paper presents a new structure form of prestressed anchor block with arch-shaped cavity used in spillway pier structures. With the arch-shaped cavity, the problem of excessive tensile stress associated with the rectangular-shaped cavity can be resolved. Five different finite element models with different arch heights were generated. These models were used to analyze the spillway pier under the loadings of two typical spillway operating Cases. The stress distribution in the pier neck and the vertical and horizontal stresses on the cavity surface of the anchor block were computed. The comparison of the results shows that using arch-shaped cavity in anchor block can effectively reduce the stress in the pier neck and on the cavity surface. When the ratio of arch height to the span is between $1 / 10$ and $1 / 7$, the stress reduction is particularly notable.
\end{abstract}

Keywords-prestressed pier; anchor block with rectangular cavity; anchor block with arch cavity.

\section{INTRODUCTION}

With the development of water resources and construction of large-scale hydro projects, the flood discharge volume of spillway structures has increased constantly. The hydraulic head is higher, the orifice size is wider, and the arc gate is exposed to an increasing thrust force. Therefore, the stress concentration in pier necks and in the areas connecting anchor blocks and piers becomes more and more critical, where a tensile stress area is formed and may lead to the cracking of the concrete [1]. In order to adjust the stress distribution in the anchor blocks and the pier necks, many researchers have carried out extensive studies to reduce the tensile stress. Chuancai $\mathrm{Li}$, Caixu He, etc., proposed the idea of reserved slots in the blocks of prestressed anchor pier in 1993 [2]. Dun Zhu and Guibi Xing [3] suggested adopting the structural form of making a slot in the pier neck, which was based on the finite element analysis results of stress distribution in the neck of large thrust prestressed pier. In 1997, Caixu He, Chuancai Li, and Yaho He studied the structural forms and the design methods of prestressed pier using theoretical analysis and simulation model tests. They proposed the structural form of slotted anchor block for the prestressed pier [4]. With this kind of anchor block, the transmission path of the pre-tension is changed, the prestressed compression force on both sides of the pier neck is increased, and the effect of prestressed force is improved. Zhaohui He, Jianhui Si, etc., have studied how to select the cavity location in the anchor block and the impact of the cavity location to the stresses in the pier neck and on the cavity surface in anchor block [5, 6].
At present the structure form of prestressed anchor block with rectangular cavity is generally adopted. However, because the pier is subjected to the forces caused by the self-weight, the prestressed anchor cables, and the high thrust of the arc gate as well as the stress concentration induced in the structure due to the reserved cavity opening, a high tensile stress, often reaching 2 to 3 $\mathrm{MPa}$, is generated on the surface of the cavity opening and cause cracking in the concrete in this area. This problem cannot be solved by simply adding reinforcement to the anchor block. Rather, it requires to analyze different forms of cavity openings and to optimize the design of anchor blocks. This paper presents a new structure form of prestressed anchor block with arched cavity. The structure form was optimized based on the force characteristics of arch structures and the particular environment of Xi River Hydroelectric Dam Spillway. A total of five cases including one rectangular cavity and four different arch shape cavities were analyzed.

\section{XI RIVER HYDROPOWER STATION}

Xi River Hydropower Station is a roller compacted concrete gravity dam with water release through dam orifices and curved sluice gates on the surface holes. The thickness of the pier is 4.0 meters. The structure type of necking prestressed anchor block with rectangular cavity is adopted at the tail part of the pier. There are 28 main prestressed anchorage cables in 7 rows and 4 layers. The eternal tonnage is $3450 \mathrm{kN}$. In addition, there are 24 horizontal secondary anchor cables in 4 rows and 6 layers. Their eternal tonnage is $2500 \mathrm{kN}$. The pull-anchor coefficient is 1.815 and the maximum total thrust of the arc gate is $53200 \mathrm{KN}$. The layout of the prestressed pier and anchor cables is shown in Figure 1.

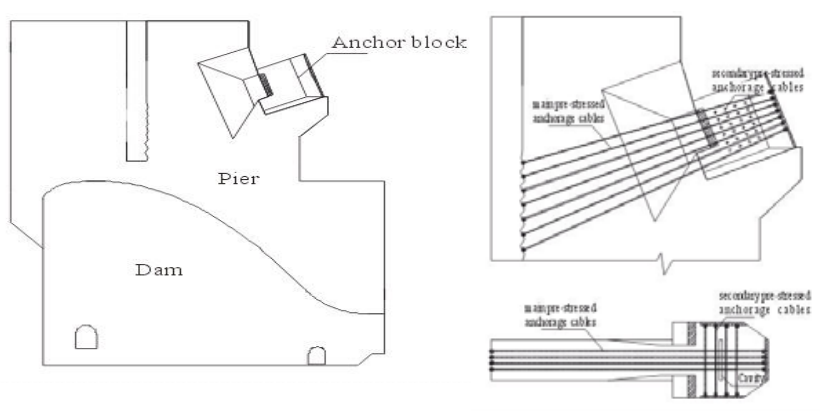

Figure 1. The layout of prestressed pier and anchor cables 


\section{ARCH STRUCTURES}

In both eastern and western countries, arch structures have been used extensively since ancient time in a wide range of constructions, such as round arches, sail arches, ribbed arches, and Gothic arches used in China, Egypt, Greek, Rome, Byzantine and so on. Circular or parabolic arches have been mostly used in modern arch structures. Initially, arch structures were mainly used in bridges and were later extended to buildings and other applications. In building constructions, arches were used mostly for roofs or above the openings of doors and windows. In the construction of hydraulic and hydro-power facilities, arch dams represent a typical application of arch-shaped structures $[7,8]$.

When an arch is subjected to different loadings, the pressure curve of the arch is different. Usually an arch is designed based on the pressure curve under the dead loads. When live loads are applied, bending moments may be induced in the arch. In this case, installation of hinges in the arch will affect the distribution of the bending moment. Similar to rigid frames, non-hinged arches are used when the foundation is good or the soil Case of the supports on both sides of the arch is very stable. Double-hinged arches are used more often in many applications. To accommodate possible differential settlements induced at the supports and deformation in the tie of the arch due to soft foundations, statically determinate structures of threehinged arches are preferred.

The main stress characteristics in the prestressed anchor block with arched cavity in the spillway pier structure are described as follows. The vertical loads which are equivalent to the tensile forces in the main anchor cables cause a horizontal thrust. The secondary anchor cables around the cavity are equivalent to the tie rods of the arch so that the main internal force in the arch is the axial force. Thus, the use of arched cavity will definitely reduce the tensile stress in the anchor block.

\section{ARCHED CAVITY AND SPILLWAy OPERATING CASES}

In this study, the shape of the arched cavity is expressed by the typical arch axis equation, namely $y=4 f x(l-x) / l^{2}$ where $l$ is the cavity length, $f$ is the arch height, and $x$ is a variable measuring the distance from the point of calculation to one end of the cavity. Five different

arch heights, $0, l / 20,2 l / 20,3 l / 20$, and $4 l / 20$, were used in the analysis to generate five different finite elements models for the anchor block. The horizontal length of the cavity is 4 meters, the cavity thicknesses is 0.3 meters, and the arch heights are $0 \mathrm{~m}, 0.2 \mathrm{~m}, 0.4 \mathrm{~m}, 0.6 \mathrm{~m}$, and 0.8 $\mathrm{m}$, respectively . The finite element models of the pier and the anchor block are shown in Figure 2 and Figure 3.

Two typical operating Cases of the spillway are selected for the analysis. They are bilateral opening of the arc gate with normal impoundment (Case 1) and unilateral opening of the arc gate with normal impoundment (Case 2). These operating Cases and the combination of loads in each Case are shown in Table I.

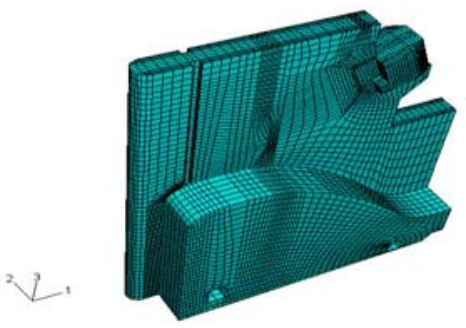

Figure 2. The finite element model of the prestressed pier

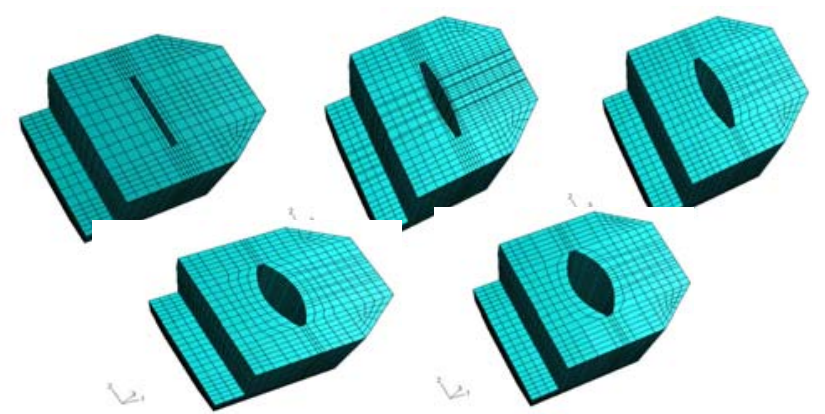

Figure 3. Five different finite element models of the anchor block

TABLE I. CASE AND COMBINATIONS OF LOADS

\begin{tabular}{|c|c|c|c|c|c|c|c|c|c|c|c|}
\hline \multirow[b]{2}{*}{. } & \multicolumn{11}{|c|}{ LOAD } \\
\hline & $\begin{array}{l}\text { Concrete } \\
\text { weight }\end{array}$ & $\begin{array}{l}\text { Prestressed } \\
\text { force }\end{array}$ & $\begin{array}{l}\text { Weight of } \\
\text { Device }\end{array}$ & $\begin{array}{l}\text { Arc gate sill } \\
\text { pressure }\end{array}$ & $\begin{array}{l}\text { Beam } \\
\text { thrust }\end{array}$ & $\begin{array}{l}\text { Single hinge } \\
\text { thrust }\end{array}$ & $\begin{array}{l}\text { Total } \\
\text { thrust }\end{array}$ & $\begin{array}{c}\text { Water } \\
\text { pressure }\end{array}$ & $\begin{array}{l}\text { Uplift } \\
\text { pressure }\end{array}$ & $\begin{array}{c}\text { Wave } \\
\text { pressure }\end{array}$ & $\begin{array}{c}\text { Silt } \\
\text { pressure }\end{array}$ \\
\hline $\begin{array}{c}\text { Case } \\
1\end{array}$ & V & V & V & $V$ & & & V & V & $\vee$ & $\vee$ & $V$ \\
\hline $\begin{array}{c}\text { Case } \\
2\end{array}$ & V & $V$ & $\vee$ & $\vee$ & V & V & & $V$ & V & V & V \\
\hline
\end{tabular}

\section{NUMERICAL ANALYSIS AND RESULTS}

Using ABAQUS finite element program, the piers with different arched cavity shapes under different load combinations were analyzed. The results of stress distributions in the pier neck and on the cavity surface of the anchor block were collected for different cases and evaluated. The maximum principal tensile stresses in the 
pier neck for five different arch heights are shown in Table II, and the vertical and horizontal maximum stresses on the cavity surface are shown in Table III. It can be seen from Table II that the maximum principal tensile stress in the pier neck is significantly reduced after using the structure form of rectangular anchor block with arched cavity. When the arch height is $0.6 \mathrm{~m}$, the maximum tensile stress is minimum. Under Case 1 the maximum principal tensile stress was reduced from 1.0 $\mathrm{MPa}$ to 0.6 $\mathrm{MPa}$. Under Case 2 the maximum principal tensile stress was reduced from $1.3 \mathrm{MPa}$ to $0.9 \mathrm{MPa}$. Table 3 shows that both vertical and horizontal normal stresses on the cavity surface decrease too after using the form of arched cavity. When the arch height is in the range of $0.6 \mathrm{~m}$ to $0.8 \mathrm{~m}$, which represents the ratio of arch height to the span varying from $1 / 10$ to $1 / 7$, the reduction in the stress is particularly notable. The results indicate that the adoption of arch-shaped cavity can effectively reduce the tensile stress in the pier neck and on the cavity surface and thus it can be used to solve the problem of excessive tensile stress happened in the case of anchor blocks with rectangular cavities.

TABLE II. MAXIMUM PRINCIPAL TENSILE STRESS IN PIER NECK SURFACE

\begin{tabular}{|c|c|c|c|c|c|}
\hline Arch height (m) & Maximum & ress $(\mathrm{MPa})$ & Arch height (m) & \multicolumn{2}{|c|}{ Maximum principal tensile stress (Mpa) } \\
\hline \multirow{2}{*}{0.0} & Case 1: & 1.0 & \multirow{2}{*}{0.2} & Case 1: & 0.7 \\
\hline & Case 2: & 1.3 & & Case 2: & 1.1 \\
\hline \multirow{2}{*}{0.4} & Case 1: & 0.6 & \multirow{4}{*}{0.6} & Case 1: & 0.6 \\
\hline & Case 2: & 1.0 & & Case 2: & 0.9 \\
\hline \multirow{2}{*}{0.8} & Case 1: & 0.6 & & & \\
\hline & Case 2: & 1.0 & & & \\
\hline
\end{tabular}

TABLE III. STRESS ON ANCHOR BLOCK CAVITY SURFACE

\begin{tabular}{|c|c|c|c|c|c|}
\hline \multirow{2}{*}{$\begin{array}{l}\text { Arch heights } \\
\text { (m) }\end{array}$} & \multirow{2}{*}{ Case } & \multicolumn{2}{|c|}{ Vertical stress (MPa) } & \multicolumn{2}{|c|}{ Horizontal stress (MPa) } \\
\hline & & Up surface & down surface & Up surface & down surface \\
\hline \multirow{2}{*}{0.0} & Case 1 & 1.3 & 2.5 & 0.9 & 1.7 \\
\hline & Case 2 & 1.0 & 2.5 & 1.6 & 1.6 \\
\hline \multirow{2}{*}{0.2} & Case 1 & 1.3 & 2.4 & 1.0 & 1.7 \\
\hline & Case 2 & 1.4 & 2.4 & 1.6 & 1.6 \\
\hline \multirow{2}{*}{0.4} & Case 1 & 1.3 & 2.4 & 0.0 & 1.6 \\
\hline & Case 2 & 0.8 & 2.4 & 1.5 & 1.5 \\
\hline \multirow{2}{*}{0.6} & Case 1 & 1.1 & 2.3 & 0.0 & 1.5 \\
\hline & Case 2 & 0.9 & 2.3 & 1.4 & 1.4 \\
\hline \multirow{2}{*}{0.8} & Case 1 & 1.1 & 2.3 & -0.5 & 0.8 \\
\hline & Case 2 & 0.9 & 2.3 & 1.3 & 1.4 \\
\hline
\end{tabular}

\section{CONCLUSIONS}

For solving the problem of excessive tensile stress induced in the prestressed anchor block with rectangular cavity used in spillway pier structures, this paper utilizes the characteristics of arch structures and presents a new structure form of prestressed anchor block with arch cavity. Five finite element models of the prestressed anchor block with different arch heights were generated. These models under the loadings of two typical operating Cases of the spillway structure were analyzed using the ABAQUS finite element program. The results of the stress distribution in the pier neck and on the surface of the cavity were evaluated and compared. It indicates that the use of anchor block with arch-shaped cavity can effectively reduce the stress concentration in the pier neck and cavity surface which happens in the structure type of anchor block with rectangular cavity. When the ratio of the arch height to the span is between $1 / 10$ and $1 / 7$, the stress reduction is particularly evident. The study provides a new direction in the design of prestressed anchor blocks in terms of reducing the amount of anchor cables used in the spillway pier structures.

\section{REFERENCES}

[1] Liu Junbai,Lin Key. Prestressed pier technology and application of water resources and hydropower in the China [J]. The Hydro-Electric Power, 1991,24(5):20-24.

[2] Li Chuancai,He Caixu,Xiao Mingjun. A new structure type research of large thrust bearing radial gate [J]. The China Civil Engineering Journal, 1993,17(9):43-46.

[3] Zhu Dun,Xing Guibi. Preliminary study of radial gate prestressed pier neck and slotted design [J]. The Journal of Hydro-Electric Power, 1994,19(1):18-26.

[4] He Caixu,Li Chuancai,He Yabo. Design method of large thrust prestressed pier [J]. The Water Resources and Hydropower Technology. 1997,31(6):24-29.

[5] He Zhaosheng,Ling Yun. The application of new prestressed pier structures in the Jinghong Hydropower Project [J]. The HydroElectric Power, 2008,32(4):50-53.

[6] Si Jianhui,Jian Zheng,Pu Meng, Qiao Optimization of anchor block cavity position in prestressed pier [J]. Engineering Journal of Wuhan University. 2010,43(1):43-50. 
[7] ZHANG Guo-xin, ZHU Bo-fang, YANG Bo, ZHUYin-bang. Review and prospect of hydraulic structure research [J]. Journal of China Institute of Water Resources and Hydropower Research. 2008, 6(4):269-278.
[8] CHEN Hou-qun. Review and prospect of seismic study on concrete hydraulic structures [J]. Journal of China Institute of Water Resources and Hydropower Research. 2008, 6(4):245-257. 